\title{
Dynamic regimes of the Greenland Ice Sheet emerging from interacting melt-elevation and glacial isostatic adjustment feedbacks
}

\author{
Maria Zeitz ${ }^{1,2}$, Jan M. Haacker ${ }^{1,2,3}$, Jonathan F. Donges ${ }^{1,4}$, Torsten Albrecht ${ }^{1}$, and Ricarda Winkelmann ${ }^{1,2}$ \\ ${ }^{1}$ Earth System Analysis, Potsdam Institute for Climate Impact Research, Member of the Leibniz Association, Telegrafenberg \\ A31, 14473 Potsdam, Germany \\ ${ }^{2}$ Institute for Physics and Astronomy, University of Potsdam, Potsdam, Germany \\ ${ }^{3}$ Delft University of Technology, Faculty of Civil Engineering and Geosciences, Department of Geoscience and Remote \\ Sensing, Delft, The Netherlands \\ ${ }^{4}$ Stockholm Resilience Centre, Stockholm University, Kräftriket 2B, 11419 Stockholm, Sweden
}

Correspondence: Maria Zeitz (maria.zeitz@ pik-potsdam.de), Ricarda Winkelmann (ricarda.winkelmann@ pik-potsdam.de)

\begin{abstract}
The stability of the Greenland Ice Sheet under global warming is governed by a number of dynamic processes and interacting feedback mechanisms in the ice sheet, atmosphere and solid Earth. Here we study the long-term effects due to the interplay of the competing melt-elevation and glacial isostatic adjustment (GIA) feedbacks for different temperature step forcing experiments with a coupled ice-sheet and solid-Earth model. Our model results show that for warming levels above $5 \quad 2^{\circ} \mathrm{C}$, Greenland could become essentially ice-free on the long-term, mainly as a result of surface melting and acceleration of ice flow. These ice losses can be mitigated, however, in some cases with strong GIA feedback even promoting the partial recovery of the Greenland ice volume. We further explore the full-factorial parameter space determining the relative strengths of the two feedbacks: Our findings suggest distinct dynamic regimes of the Greenland Ice Sheets on the route to destabilization under global warming - from recovery, via quasi-periodic oscillations in ice volume to ice-sheet collapse. In the recovery regime, the initial ice loss due to warming is essentially reversed within 50,000 years and the ice volume stabilizes at 61-93\% of the present-day volume. For certain combinations of temperature increase, atmospheric lapse rate and mantle viscosity, the interaction of the GIA feedback and the melt-elevation feedback leads to self-sustained, long-term oscillations in ice-sheet volume with oscillation periods of tens to hundreds of thousands of years and oscillation amplitudes between 15-70\% of present-day ice volume. This oscillatory regime reveals a possible mode of internal climatic variability in the Earth system on time scales on the order of 100,000 years that may be excited by or synchronized with orbital forcing or interact with glacial cycles and other slow modes of variability. Our findings are not meant as scenario-based near-term projections of ice losses but rather providing insight into of the feedback loops governing the "deep future" and, thus, long-term resilience of the Greenland Ice Sheet.
\end{abstract}




\section{Introduction}

The Greenland Ice Sheet (GrIS) holds enough water to raise global sea levels by more than $7.4 \mathrm{~m}$ and is continuously losing mass at present, thereby contributing to global sea-level rise (Morlighem et al., 2017; Frederikse et al., 2020). Current mass loss rates of $286 \mathrm{Gt} / \mathrm{yr}$ are observed, a 6-fold increase since the 1980's (Mouginot et al., 2019). Here, approximately $35 \%$ can be attributed to a decrease in climatic mass balance and $65 \%$ are due to an increase in ice discharge. While it has been suggested that the Greenland Ice Sheet could become unstable beyond temperature anomalies of $1.6-3.2{ }^{\circ} \mathrm{C}$ due to the selfamplifying melt-elevation feedback (Levermann and Winkelmann, 2016), recent studies debate whether a tipping point might have already been crossed (Robinson et al., 2012; Winkelmann et al., 2011; Boers and Rypdal, 2021). Understanding the feedback mechanisms and involved time scales at play in GrIS mass loss dynamics is necessary to understanding its stability under climatic changes.

Changing climatic conditions during the glacial cycles had a strong influence on the ice volume of the Greenland Ice Sheet. It varied from 3-7 m sea-level equivalent (that is the volume above floatation, divided by the total ocean area) in the last interglacial (from 126 to $115 \mathrm{kyrs} \mathrm{BP}$ ) to $12 \mathrm{~m}$ during the last glacial maximum (19-20 kyrs BP) (Vasskog et al., 2015), while the present day volume of the GrIS is $7.42 \mathrm{~m}$. Various processes and feedbacks in the ice sheet, atmosphere, ocean and solid Earth governing the ice dynamics, like ice-ocean interactions, the melt-elevation feedback, and the snow-albedo feedback played an important role in past transitions from interglacial to glacial and vice versa (Denton et al., 2010; Willeit and Ganopolski, 2018; Pico et al., 2018). In this way, the GrIS has been a key component in the emergence of glacial cycles and their implications for overall Earth system stability, as can also be analyzed from a dynamical systems point of view (Crucifix, 2012). Simple models also allow to study the "deep future", i.e. the future on time scales beyond the ethical time horizon as defined e.g. by Lenton et al. (2019), of the Greenland Ice Sheet and the Earth system and reveal that anthropogenic $\mathrm{CO}_{2}$ emissions affect the climate evolution for up to $500 \mathrm{kyrs}$ and can postpone the next glaciation (Talento and Ganopolski, 2021).

One particular feedback, which, to our knowledge, has not yet been systematically studied in the context of the Greenland Ice Sheet, is the negative feedback in the interaction between the ice sheet and solid Earth (Pico et al., 2018). Here we aim to close this research gap, by systematically exploring how the feedback between solid Earth, ice, and climatic mass balance and their interactions affect the long term response of the Greenland Ice Sheet.

Changes in ice load lead to glacial isostatic adjustment (GIA), a decrease in ice load initiates an uplift with characteristic time scales of hundreds to thousand of years (Barletta et al., 2018; Whitehouse et al., 2019). Currently observed post-glacial uplift rates in Greenland range between $-5.6 \mathrm{~mm} / \mathrm{yr}$ and $18 \mathrm{~mm} / \mathrm{yr}$ (Adhikari et al., 2021; Wahr et al., 2001; Dietrich et al., 2005; Schumacher et al., 2018; Khan et al., 2008). Some studies suggest that uplift rates are higher in the South East, where the Iceland hot spot has possibly passed, which can be associated with locally low viscosities in the upper mantle (Khan et al., 2016).

The viscous bedrock response is generally assumed to be slow compared to ice losses, with characteristic response time scales of tens to hundreds of millennia. However, several studies suggest that the viscosity of the asthenosphere and the upper mantle varies spatially and could be locally lower than previously thought (e.g. in Iceland, Patagonia, the Antarctic peninsula, 
Alaska). This implies that the time scale of the viscous response to changes in ice load might be much shorter, e.g. close to tens or hundreds of years (Whitehouse et al., 2019). The elastic response component responds on an even faster time scale to changes in ice load, e.g. the 2012 extreme melt event caused a significant peak in GPS measured uplift rates (Adhikari et al., 2017). A model of the solid Earth can help to interpret the GPS measurements in order to distinguish the elastic uplift caused by recent mass losses from the delayed viscous uplift caused by the retreat of ice since the last glacial maximum, and deduce solid earth parameters like mantle viscosity and lithospere thickness (Adhikari et al., 2021; Schumacher et al., 2018).

Efforts to model the solid earth response to changes in ice load range from local one-dimensional representations of the bedrock uplift to full three-dimensional models. The ELRA-type of model represents the solid earth as an Elastic Lithosphere and a Relaxing Asthenosphere by assigning a single time constant to the uplift response (Le Meur and Huybrechts, 1996; Zweck and Huybrechts, 2005). These models are computationally efficient and are often coupled to ice-sheet models in longterm simulations (Robinson et al., 2012). The Lingle-Clark model expands the elastic plate lithosphere with a viscous halfspace and solves the equations explicitly in time (Lingle and Clark, 1985; Bueler et al., 2007). The relaxation time of the solid earth then depends on the spatial wavelength of the perturbation in ice load. However, this model uses only one constant value for the mantle viscosity, it does not include vertical or horizontal variations, nor does it solte the sea-level equation including self-consistent water-load changes or the rotational state of the Earth (Farrell and Clark, 1976; Hagedoorn et al., 2007) Such a model can be expanded to include more layers, e.g. the lower mantle, however, it becomes more difficult to constrain (Lau et al., 2016). One-dimensional solid earth models explicitly consider the spherical shape of the Earth instead of assuming a half space (Tosi et al., 2005; Fleming and Lambeck, 2004; Simpson et al., 2009; Lambeck et al., 2014). However, they do not represent lateral variations in solid-Earth parameters. Three dimensional models, which resolve not only several layers of the vertical dimension, but include additional variability in the horizontal direction, are developed to account for the ongoing discovery of lateral variations in viscosity and lithosphere thickness (Khan et al., 2016; Whitehouse, 2018; Whitehouse et al., 2006, 2019; Haeger et al., 2019; Martinec, 2000). A laterally varying 3D model can change the estimate of projected global mean sea-level rise due to an ice-sheet collapse in the West-Antarctic by up to 10\% compared to a 1D model (Powell et al., 2021). Inferred values for mantle viscosities can span several orders of magnitude and therefore substantially impact the estimate of bedrock uplift rates as a response to present day ice losses (Powell et al., 2020). So far the coupling efforts between 3D solid-Earth models and physical ice-sheet models have been focused mostly on the Antarctic Ice Sheet, exploring the feedback between solid Earth and ice sheets and its potential to dampen or inhibit unstable ice sheet retreat (Gomez et al., 2013; De Boer et al., 2014; Gomez et al., 2018, 2020). Self-gravitation effects affect the stability of the grounding line (Whitehouse et al., 2019; Pollard et al., 2017) and GIA models which self-consitently solve the sea-level equation are crucial. Ongoing work focuses on the northern hemisphere, coupling for instance the Parallel Ice Sheet Model PISM to the solid-Earth model VILMA.

Similarly, modeling efforts of the climatic mass balance of the Greenland Ice Sheet range from computationally efficient temperature index models over energy balance models to sophisticates regional climate models, an overview can be found in the model intercomparison effort by Fettweis et al..

The response of the solid earth to ice loss can be part of a negative, meaning counteracting or dampening, feedback loop, called glacial isostatic adjustment (GIA) feedback, that can mitigate further ice loss. Studies focused on the GIA feedback 
in context of the Antarctic Ice Sheet suggest that the bedrock uplift can lead to a grounding line advance and therefore has a stabilizing effect on glaciers that are subjected to the marine ice sheet instability (MISI) (Whitehouse et al., 2019; Konrad et al., 2015; Kingslake et al., 2018; Bassis et al., 2017; Barletta et al., 2018). However, to our knowledge the GIA feedback has not yet been addressed in the context of the Greenland Ice Sheet, where, in comparison to the Antarctic Ice Sheet, marine terminating glaciers contribute less to mass loss. The feedback cycle we explore in this study is rather related to the self-amplifying meltelevation feedback. The melt-elevation feedback establishes a connection between ice thickness and climatic mass balance: the lower the surface elevations the higher are typically temperatures and associated melt rates (see also Figure 1, in particular the orange arrows). An initial increase in melt thins the ice, bringing the ice surface to lower elevation. Subsequently the temperature increases and amplifies both, melt rates and ice velocities, and therefore leads to further ice loss and thinning. Once a critical thickness is reached this feedback can lead to a destabilization of the ice sheet and irreversible ice loss (Levermann et al., 2013). (A similar feedback has also been known as the small ice cap instability (Weertman, 1961)).

This formulation of the melt-elevation feedback assumes a static bed, so that changes in ice thickness equal changes in ice surface altitude. GIA can mitigate this feedback: Due to bedrock deformation changes in ice thickness do not directly translate to changes in surface elevation. The loss of ice reduces the load on the bedrock and allows for a bedrock uplift, damperning the melt-elevation feedback (see blue arrows in Figure 1). Due to the high viscosity of the mantle the glacial isostatic adjustment can manifest on a slower time scale than the climatic changes which cause the ice losses in the first place.

From a static point of view a compensation of $1 / 3$ of ice thickness thinning due to GIA would be expected. In this study, we explore how the dynamic interaction of the feedbacks allows the GIA feedback not only to dampen but to (periodically) overcompensate for the melt-elevation feedback. Here we focus on the long-term stability of the Greenland Ice Sheet and how it is affected by the positive melt-elevation feedback on the one hand and the negative GIA feedback on the other hand. We use simple representations of both, the melt-elevation and the GIA feedbacks, to study the interplay between them: The meltelevation feedback is represented by an atmospheric temperature lapse rate which affects the melt rates. The GIA feedback is represented by the Lingle-Clark model, a generalization of the flat earth Elastic Lithosphere Relaxing Asthenosphere (ELRA) model (Bueler et al., 2007). The Lingle-Clark model accounts for non-local effects and different relaxation times depending on the spatial extent of the perturbation. We explore the parametric uncertainty range by varying the key parameters: asthenosphere viscosity for the bedrock uplift and the atmospheric lapse-rate for the melt-elevation feedback.

We use the Parallel Ice Sheet Model (PISM) (the PISM authors, 2018; Bueler and Brown, 2009) coupled to the Lingle-Clark solid-Earth model (Bueler et al., 2007) in order to explore the interaction between the self-amplifying and the dampening feedback. The models and the experimental design are presented in Section 2. The warming experiments use an idealized temperature forcing and are analyzed in Section 3, followed by a discussion in Section 4. 


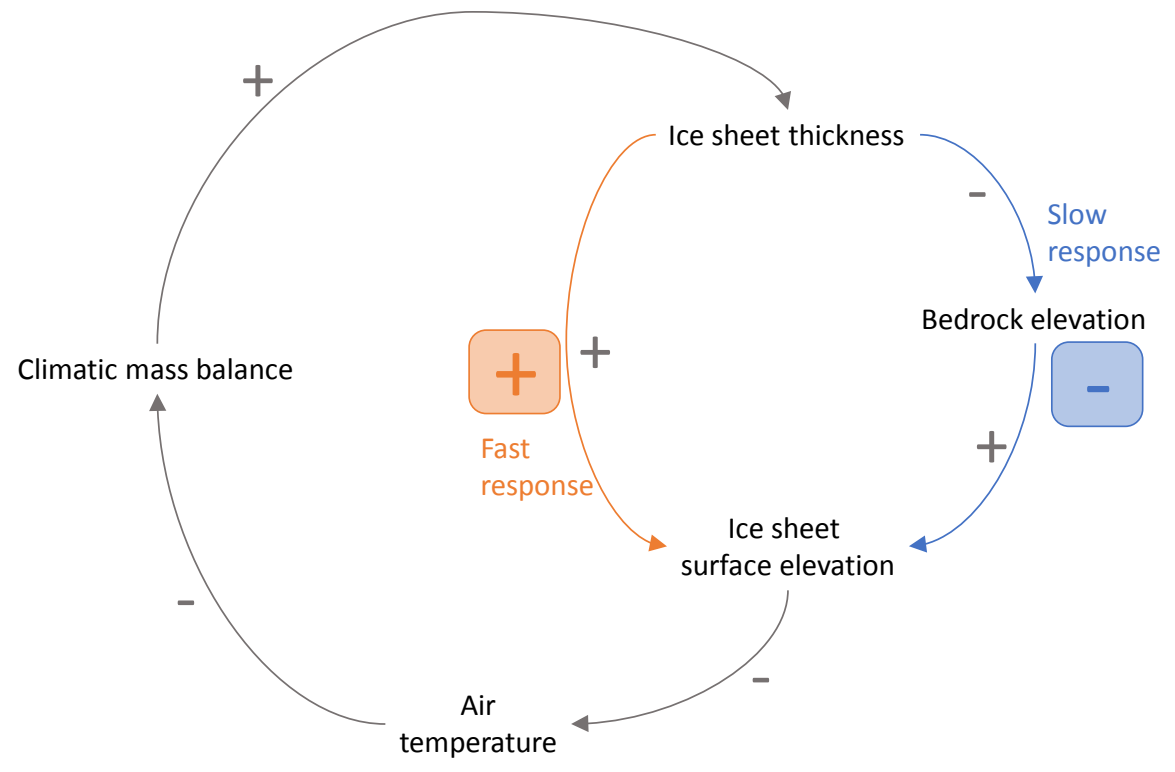

Figure 1. Interacting feedback loops for the proposed glacial isostatic adjustment feedback (GIA feedback). The orange part indicates the melt-elevation feedback: Higher air temperatures lead to decreasing climatic mass balance. This in turn leads to a decreasing ice thickness and in consequence to a decreasing ice surface elevation. If the surface elevation decreases, the air temperature rises due to the atmospheric lapse rate. This further decreases the climatic mass balance and leads to a positive (enhancing) feedback cycle. The timescale of this feedback cycle is driven by changes in the climate and is typically comparably fast. The blue part shows the counteracting mechanism of the ice loadbedrock uplift feedback. The decreasing ice thickness reduces the load on the bedrock, which leads to isostatic adjustment and therefore an uplift of the bedrock elevation. This mechanism partly counteracts the decrease in ice surface elevation and thus mitigates further increase in temperature. The timescale of this feedback loop depends on the rate of ice retreat and on the viscosity of the upper Earth mantle.

\section{Methods}

\subsection{Numerical modeling}

\subsubsection{Ice-sheet dynamics with the Parallel Ice Sheet Model PISM}

The Parallel Ice Sheet Model, PISM is a thermomechanically coupled finite difference ice-sheet model which combines the 5 shallow-ice approximation (SIA) in regions of slow-flowing ice and the shallow-shelf approximation (SSA) of the Stokes flow stress balance in ice streams and ice shelves (Bueler and Brown, 2009; Winkelmann et al., 2011; the PISM authors, 2018). The internal deformation of ice is described by Glen's flow law, here the flow exponents $n_{\mathrm{SSA}}=3$ and $n_{\mathrm{SIA}}=3$ are used. We use the enhancement factors $E_{\mathrm{SSA}}=1$ and $E_{\mathrm{SIA}}=1.5$ for the SSA and the SIA stress balance respectively. 
The sliding is described by a pseudo-plastic power law, relating the basal stress to the yield stress. The yield stress is determined from parameterized till material properties and the effective pressure of the saturated till via the Mohr-Coulomb criterion (Bueler and van Pelt, 2015).

\subsubsection{Earth deformation model}

5 While global GIA models with sea-level coupling are available, to our knowledge no coupling efforts between ice-dynamics and solid-Earth models have been undertaken for the Greenland Ice Sheet specifically. Here, the deformation of the bedrock in response to changing ice load is described with the Lingle-Clark (LC) model (Lingle and Clark, 1985; Bueler et al., 2007), incorporated as solid-earth module in PISM. In this model the response time of the bed topography depends on the wavelength of the load perturbation for a given asthenosphere viscosity (Bueler et al., 2007). The LC model uses two layers to model the solid earth: the viscous mantle is approximated by a half space of viscosity $\nu$ and density $\rho_{r}$, complemented by an elastic layer of flexural rigidity $D$ describing the lithosphere. The response of the elastic lithosphere happens instantaneously, while the response time of the viscous mantle lies between decades and tens of millennia, depending on both, the viscosity of the mantle and the wavelength of the change in load. While the Lingle-Clark model is not considering local changes to viscosity or lithosphere thickness (Milne et al., 2018; Mordret, 2018; Khan et al., 2016) and approximates the earth as a half space, the relatively small spatial extent of the simulation region allows for such an approximation.

The resulting partial differential equation for vertical displacement $u$ of the bedrock can be described by

$2 \nu|\nabla| \frac{\partial u}{\partial t}+\rho_{r} g u+D \nabla^{4} u=\sigma_{z z}$.

with $g$ being the gravitational acceleration of the earth and $\sigma_{z z}$ the ice load force per unit area (Bueler et al., 2007).

Here the flexural rigidity $D$ is assumed to be $5 \times 10^{24} \mathrm{Nm}$, assuming a thickness of $88 \mathrm{~km}$ for the elastic plate lithosphere (Bueler et al., 2007). The mantle density $\rho_{r}$ is approximated with $3300 \mathrm{~kg} / \mathrm{m}^{3}$.

\subsubsection{Climatic mass balance and temperature forcing}

The climatic mass balance in PISM is computed with the positive degree day (PDD) model from $2 \mathrm{~m}$-air temperature and precipitation given as inputs (Braithwaite, 1995). Here we use a yearly cycle of monthly averages from 1958 to 1967 of the outputs of the regional climate model RACMO v2.3 (Noël et al., 2019) in order to mimic preindustrial climate. The warming is implemented as a spatially uniform instantaneous shift in temperature. The temperature forcing itself has a yearly cycle, with the temperature shift in winter being twice as high as in summer. This corresponds to an average Arctic amplification of $150 \%$ (see also Robinson et al. (2012)).

The PDD method uses the spatially uniform standard deviation $\sigma=4.23$, the melt factors for snow and for ice $m_{i}=$ $8 \mathrm{mmK}^{-1} \mathrm{day}^{-1}, m_{s}=3 \mathrm{mmK}^{-1}$ day $^{-1}$ (PISM default) respectively. The melt-elevation feedback is approximated by an atmospheric temperature lapse rate $\Gamma$, so that local changes in the ice-sheet topography alter the temperature as

$T_{i j}=T_{i j, \text { input }}-\Gamma \cdot \Delta h_{i j}$ 
with $T_{i j}$ being the effective temperature at grid cell $i, j$ feeding into the PDD model. $T_{i j \text {,input }}$ is the temperature at $i, j$ given by the input, without any lapse rate correction, $\Gamma$ is a spatially constant air-temperature lapse rate. $\Delta h_{i, j}=h_{t, i j}-h_{0, i j}$ is the local difference in surface elevation at $i, j$ at time $t$, compared to a reference topography $h_{0}$. Here we use the initial state for $h_{0}$. The value of the lapse rate $\Gamma$, and thereby the strength of the melt-elevation feedback, is varied between $5 \mathrm{~K} / \mathrm{km}$ and $7 \mathrm{~K} / \mathrm{km}$ in the experiments. The yearly precipitation cycle remains prescribed, the local temperature affects how much of the precipitation is perceived as snow and therefore adds to the accumulation: at a temperature above $2^{\circ} \mathrm{C}$, all precipitation is perceived as rain, below $0^{\circ} \mathrm{C}$ all is perceived as snow, with a linear interpolation between the two states.

\subsection{Experimental design}

Here we use a spatial resolution in $\mathrm{x}$ and $\mathrm{y}$ direction of $15 \mathrm{~km}$ in order to do many simulations over 0.5 million years. The spatial resolution in z-direction is quadratically decreasing from $36 \mathrm{~m}$ in the cell closest to the bedrock to $230 \mathrm{~m}$ in the top grid cell of the simulation box (at $4000 \mathrm{~m}$ above bedrock).

The temperature forcing is a spatially uniform step forcing, which is applied from $t=0$ over the whole simulation time. Additional local temperature changes happen due to the atmospheric temperature lapse rate, as shown above. We explore different values for the atmospheric lapse rate in order to estimate the response of the system to changes in the strength of the melt-elevation feedback.

The ice-ocean interaction is modeled via PICO, with ocean temperatures and salinities taken from the World Ocean Atlas version 2 (Zweng et al., 2018; Locarnini et al., 2019). Temperatures and salinities are averaged at bottom depth over the extended drainage sectors of the GrIS. For the extended sectors, the drainage sectors of Rignot and Mouginot (2012) are extended linearly into the ocean. The warming signal at depth generally stabilizes at lower levels than the atmospheric or sea surface warming, here we assume that only $70 \%$ of atmospheric warming reaches the ocean ground (see also Albrecht et al. (2020)). Calving is modeled as a combination of eigencalving (Winkelmann et al., 2011; Levermann et al., 2012) and von-Mises calving (Morlighem et al., 2016) with constant calving parameters.

\subsubsection{Initial state}

The initial state is in equilibrium for constant climate conditions. The misfits of the initial state compared to observed velocities (Joughin et al., 2018) and thicknesses (Morlighem et al., 2017) and to modelled climatic mass balance (Noël et al., 2019) are shown in the Supplementary Material in Figures S1, S2 and S3. All simulations are run at a spatial horizontal resolution of $15 \mathrm{~km}$. The basic dynamics of the melt-elevation feedback and the GIA feedback are well captured at this resolution, which allows to explore the parameter space effectively. However, a lot of features of the complex flow of outlet glaciers are not captured at this resolution. 
Table 1. Parameters used in experiments

\begin{tabular}{rrr}
\hline Name & Parameter & Value \\
\hline$\Delta T$ & Temperature increase & $1.5,2,3 \mathrm{~K}$ \\
$\Gamma$ & Atmospheric temperature lapse rate & $5-7 \mathrm{~K} / \mathrm{km}$ \\
$\nu$ & Mantle viscosity & $1 \times 10^{-19}-\times 10^{21} \mathrm{~Pa} \cdot \mathrm{s}$ \\
\hline
\end{tabular}

\subsubsection{Choice of model parameters}

We chose to vary along three main parameters. On the one hand, we vary the strength of the melt-elevation feedback by varying the atmospheric temperature lapse rate $\Gamma$ between $5 \mathrm{~K} / \mathrm{km}$ and $7 \mathrm{~K} / \mathrm{km}$. Many ice-sheet models use the free air moist adiabatic lapse rate (MALR), which ranges between 6-7 K/km (Gardner et al., 2009) for high humidity, but assumed to be higher in cold temperatures when the air is dry (Fausto et al., 2009). However, the mean slope lapse rates measured in Greenland and on other ice caps in the Arctic tend to be lower than the MALR and show seasonal variation (Fausto et al., 2009; Gardner et al., 2009; Steffen and Box, 2001; Hanna et al., 2005). By using spatially and temporally constant lapse rates between 5-7 K/km we try to cover a realistic range in lapse rates.

In addition, the response time and strength of the bedrock to changes in ice load is determined by the mantle viscosity $\nu$, varied between $1 \times 10^{19} \mathrm{~Pa} \cdot \mathrm{s}$ and $5 \times 10^{21} \mathrm{~Pa} \cdot \mathrm{s}$. This range is larger than the values of the upper mantle viscosity given in the literature, which still range over more than two order of magnitude over Greenland alone, usually around $1 \cdot 10^{20} \mathrm{~Pa} \cdot \mathrm{s}$ to $5 \cdot 10^{21} \mathrm{~Pa} \cdot \mathrm{s}$, but local values from $1 \cdot 10^{18} \mathrm{~Pa} \cdot \mathrm{s}$ to $1 \cdot 10^{23} \mathrm{~Pa} \cdot \mathrm{s}$ cannot be ruled out (Tosi et al., 2005; ?; Mordret, 2018; Khan et al., 2016; Wahr et al., 2001; Peltier and Drummong, 2008; Larour et al., 2019; Le Meur and Huybrechts, 1996, 1998; Milne et al., 2018; Fleming and Lambeck, 2004; Lecavalier et al., 2014; Lambeck et al., 2014; Lau et al., 2016). Ice retreat itself is affected by the temperature anomaly, here varied between $1.5 \mathrm{~K}$ and $3.0 \mathrm{~K}$ global warming (note the arctic amplification of $150 \%$ leading to higher local temperature anomalies).

\section{Results}

Here, we analyze how the strengths of the melt-elevation feedback and the GIA feedback influence the long term dynamics of the Greenland Ice Sheet in PISM simulations.

\subsection{Temporal evolution of ice volume under temperature forcing depending on atmospheric lapse rate and mantle viscosity}

The ice losses in simulations with applied warming are affected by both, the amplifying melt-elevation feedback and the mitigating GIA feedback. The interaction of both feedbacks allows for a variety of dynamic regimes, depending on the amount of warming on the one hand and the parameters describing the feedback strength on the other hand. 


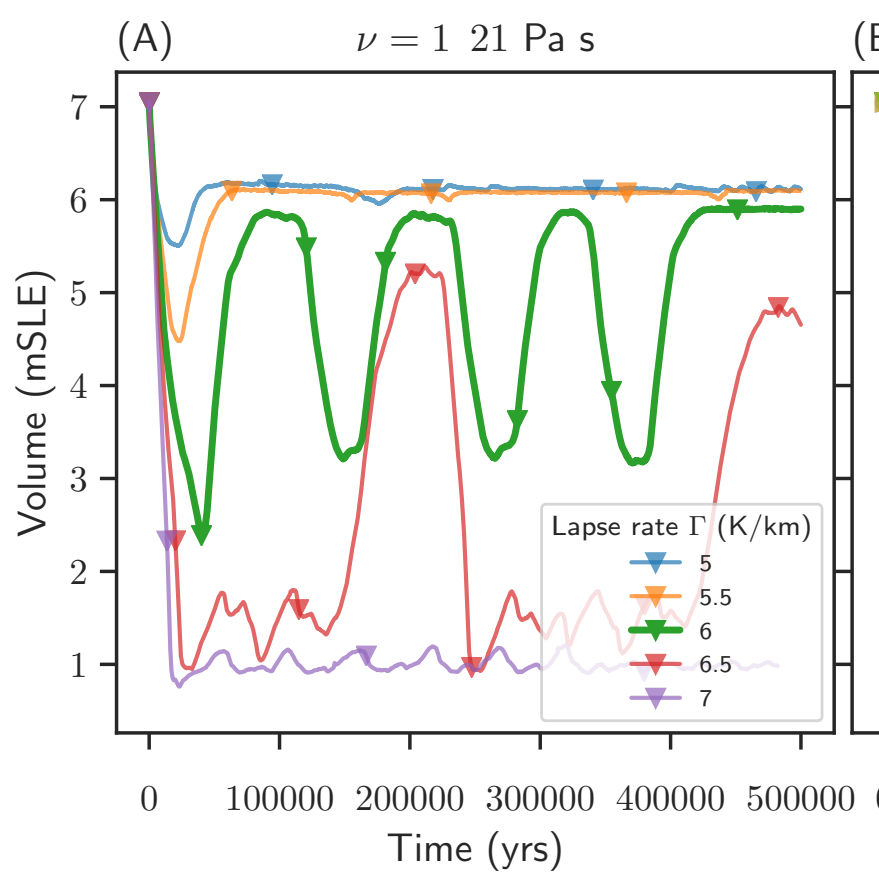

(B) Lapse rate $\Gamma=6 \mathrm{~K} / \mathrm{km}$

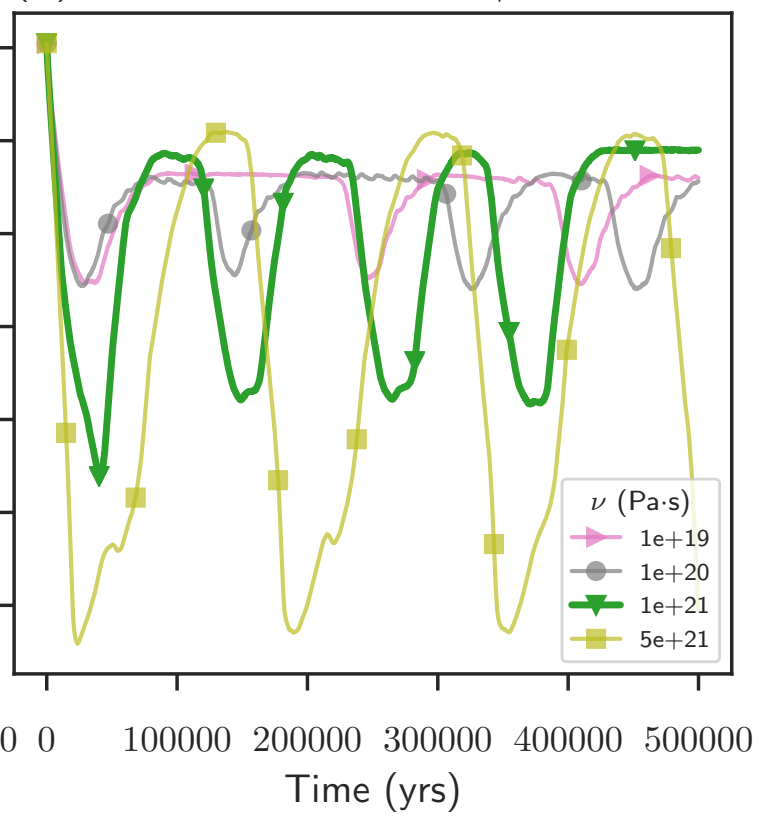

Figure 2. Temporal evolution of Greenland Ice Sheet volume at a temperature anomaly of $\Delta T=2 \mathrm{~K}$. Depending on the atmospheric temperature lapse rate (between 5 and $7 \mathrm{~K} / \mathrm{km})(\mathbf{A})$ and on the mantle viscosity (between $1 \times 10^{19}$ and $\left.5 \times 10^{21} \mathrm{~Pa} \cdot \mathrm{s}\right)(\mathrm{B})$ distinct regimes of dynamic responses are observed, including recovery, oscillations and permanent of ice volume.

At a given temperature anomaly (here $\Delta T=2 \mathrm{~K}$ ) and a given mantle viscosity (here $\nu=1 \times 10^{21} \mathrm{~Pa} \cdot \mathrm{s}$ ), both, the rate and magnitude of the initial volume loss increase with increasing air temperature lapse rate, i.e. a stronger melt-elevation feedback (see Figure 2 (A)). With a lapse rate of $\Gamma=5 \mathrm{~K} / \mathrm{km}$, at the low end of the tested range, a recovery after an initial ice loss is observed, the ice sheet loses approx $1.5 \mathrm{~m}$ sea-level equivalent in volume, before stabilizing at $6 \mathrm{~m}$ SLE after approx. $50 \mathrm{kyrs}$ ( $1 \mathrm{~m}$ SLE corresponds to approx. $361800 \mathrm{Gt}$ of ice). With an increasing lapse rate and thereby increasing strength of the meltelevation feedback the ice volume may still recover after a stronger initial loss. At sufficiently high lapse rates the recovered state is not stable on long time scales. A self-sustained oscillation of repeated ice losses and gains is observed for $\Gamma=6 \mathrm{~K} / \mathrm{km}$ with an oscillation time scale of approx. $109 \mathrm{kyrs}$. Increasing the lapse rate even further, to $\Gamma=7 \mathrm{~K} / \mathrm{km}$ does not allow the ice to recover at all, the ice volume is permanently lost.

Here, depending on the value of the lapse rate $\Gamma$ three qualitatively different response regimes are observed, (i) recovery, (ii) self-sustained oscillation, and (iii) permanent ice loss.

In contrast a constant lapse rate of $\Gamma=6 \mathrm{~K} / \mathrm{km}$, a warming of $\Delta T=2 \mathrm{~K}$ and varying mantle viscosities between $\nu=1 \times$ $10^{19}-5 \times 10^{21} \mathrm{~Pa} \cdot \mathrm{s}$ lead to self-sustained oscillations (ii) in the ice sheet volume independently of the value of the mantle viscosity (see Figure 2 (B)). The variations in mantle viscosity do not change the dynamic regime qualitatively, they affect however the time scale and the amplitude of the observed oscillations. Large values for the mantle viscosity are associated with 

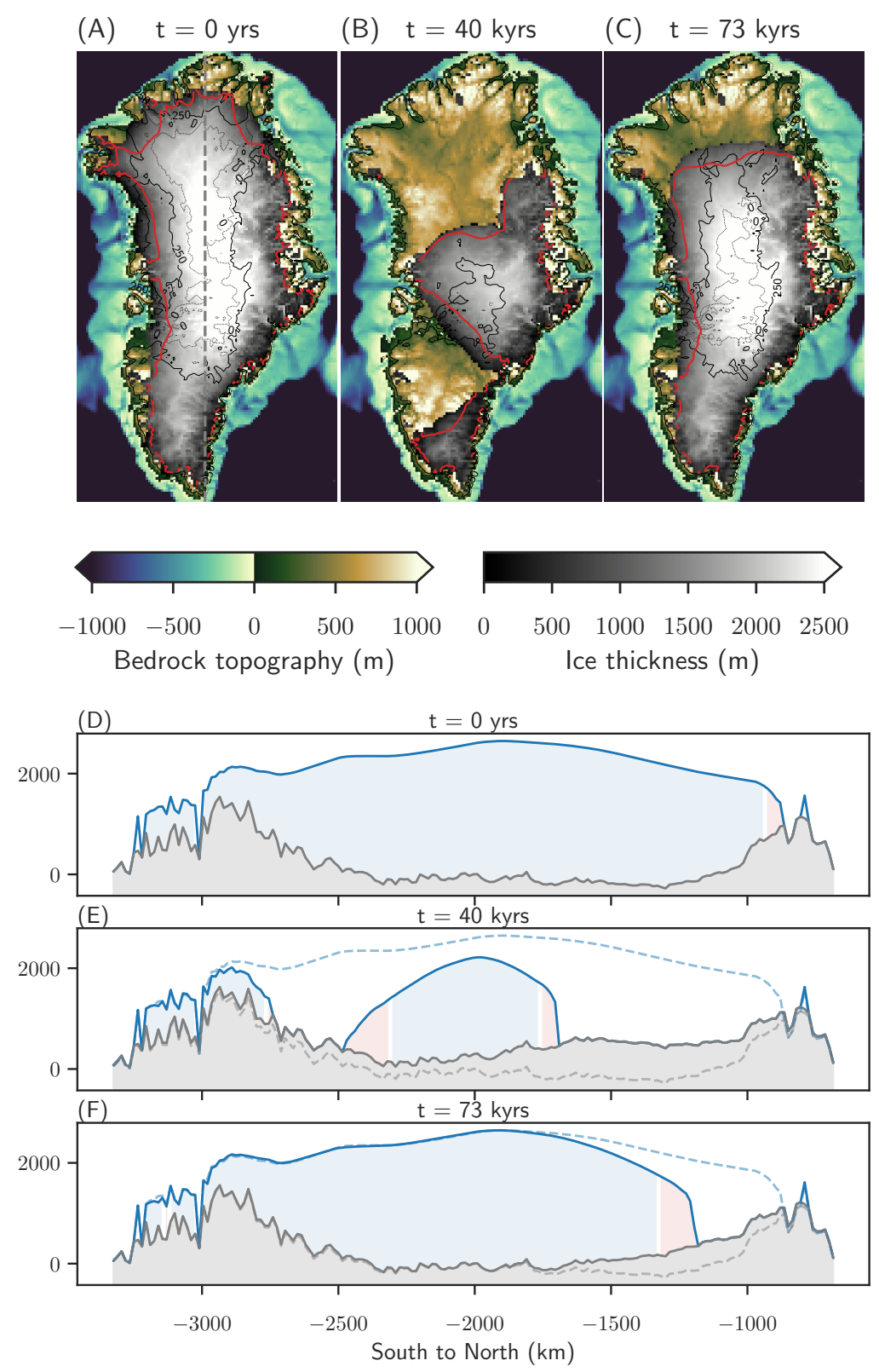

Figure 3. Spatial distribution of ice thickness at a temperature anomaly of $\Delta T=2 \mathrm{~K}$ for the parameters $\nu=1 \times 10^{21} \mathrm{~Pa} \cdot \mathrm{s}, \Gamma=6 \mathrm{~K} / \mathrm{km}$. Maps and cross-sections of the bedrock topography and ice thickness show the initial state at the start of the simulation (A,D), the state with minimal volume after $40 \mathrm{kyrs}(\mathrm{B}, \mathrm{E})$ and the recovered state after $73 \mathrm{kyrs}(\mathrm{C}, \mathrm{F})$. The red outline and the red shaded areas indicate the ablation regions. The dashed lines in $(\mathrm{E})$ and $(\mathrm{F})$ show the initial topography of the ice sheet. 
a smaller response time scale of the GIA and thereby allow for larger initial ice losses and large amplitudes of oscillation. The amplitude, here taken as the difference between the maximal and the minimal volume after an initial ice loss, increases from $1.2 \mathrm{~m}$ to $5.5 \mathrm{~m}$ by increasing the mantle viscosity from $1 \mathrm{e}+19 \mathrm{~Pa} \cdot \mathrm{s}$ to $5 \mathrm{e}+21 \mathrm{~Pa} \cdot \mathrm{s}$.

The observed oscillations in ice sheet volume (regime ii) are not perfectly periodical, therefore the concepts of periodicity

5 or frequency cannot be directly applied. This framing would require that the physical state of the ice sheet, regarding not only its volume but also spatially resolved variables like thickness distribution, velocity fields, the state of the solid earth and the climate, return to exactly the same state after one oscillation period. Instead we here use a power spectrum analysis to estimate the characteristic time of oscillation. The oscillation times in this study vary between $79 \mathrm{kyrs}$ (for $\Delta T=3 \mathrm{~K}, \nu=$ $1 \cdot 10^{21} \mathrm{~Pa} \cdot \mathrm{s}$ and $\Gamma=5.5 \mathrm{~K} / \mathrm{km}$ ) and $250 \mathrm{kyrs}$ (for $\Delta T=2 \mathrm{~K}, \nu=1 \cdot 10^{21} \mathrm{~Pa} \cdot \mathrm{s}$ and $\Gamma=6.5 \mathrm{~K} / \mathrm{km}$ ). An even longer oscillation time of $333 \mathrm{kyrs}$ is found for $\Delta T=1.5 \mathrm{~K}, \nu=1 \cdot 10^{19} \mathrm{~Pa} \cdot \mathrm{s}$ and $\Gamma=6.0 \mathrm{~K} / \mathrm{km}$, it is however seemingly an outlier: the ice sheet volume seems to recover and reach a permanently stable plateau, but after $250 \mathrm{kyrs}$ a decline in ice-sheet volume is re-initiated. The oscillation times do not seem to show a clear dependence on the values for warming, lapse rate or mantle viscosity.

The spatial configuration of the ice thickness, the bedrock topography and the equilibrium line, separating the accumulation from the ablation region in response to warming is visualized for one example simulation in the oscillation regime (ii), with the parameters $\Delta T=2 \mathrm{~K}, \nu=1 \times 10^{21} \mathrm{~Pa} \cdot \mathrm{s}$ and $\Gamma=6 \mathrm{~K} / \mathrm{km}$. We choose three points in time, representing the initial state, the state with minimal ice volume and the oscillation maximum, a recovered state which is unstable on long time scales (see Figure 3). The time evolution of the volume is depicted by the thick green curve in Figure 2. During the retreat phase, the mass loss of the ice is initiated from the north of the ice sheet. The area and volume of the ice sheet decrease and reach a minimal value after approx. $40 \mathrm{kyrs}$, with a remaining ice dome over central Greenland and a second smaller ice patch over the southern tip of Greenland. This ice loss is accompanied by an uplift of the bedrock which is most prominent in areas with complete ice loss. The maximal ice thickness decreases from $2940 \mathrm{~m}$ to $2270 \mathrm{~m}$ in the minimal volume state, attained in the 2astern region of the ice larger ice dome. The maximal bedrock uplift of $740 \mathrm{~m}$ is found in the northern region where the most ice is lost. The minimal state is also characterized by an increase in relative ablation area, $29 \%$ compared to $24 \%$ in the initial state. The maximal relative ablation area of $31 \%$ is reached approx. 500 years before the minimum of the volume is reached. Eventually, the accumulation area expands and allows the ice sheet to regrow. However, the maximally recovered ice sheet differs from the initial state in area, thickness distribution, accumulation area, and bedrock topography (see Figs. $3 \mathrm{C}$ and F). In particular the ice sheet extends much less to the north than in the initial state. The precipitation field is assumed to be constant in time, there is no feedback between the ice sheet topography and the precipitation pattern.

\subsection{Competing positive melt-elevation and negative GIA feedbacks}

30 Here we explore the competing feedbacks by varying the parameters, which determine the relative strengths of the involved feedbacks, simultaneously. 


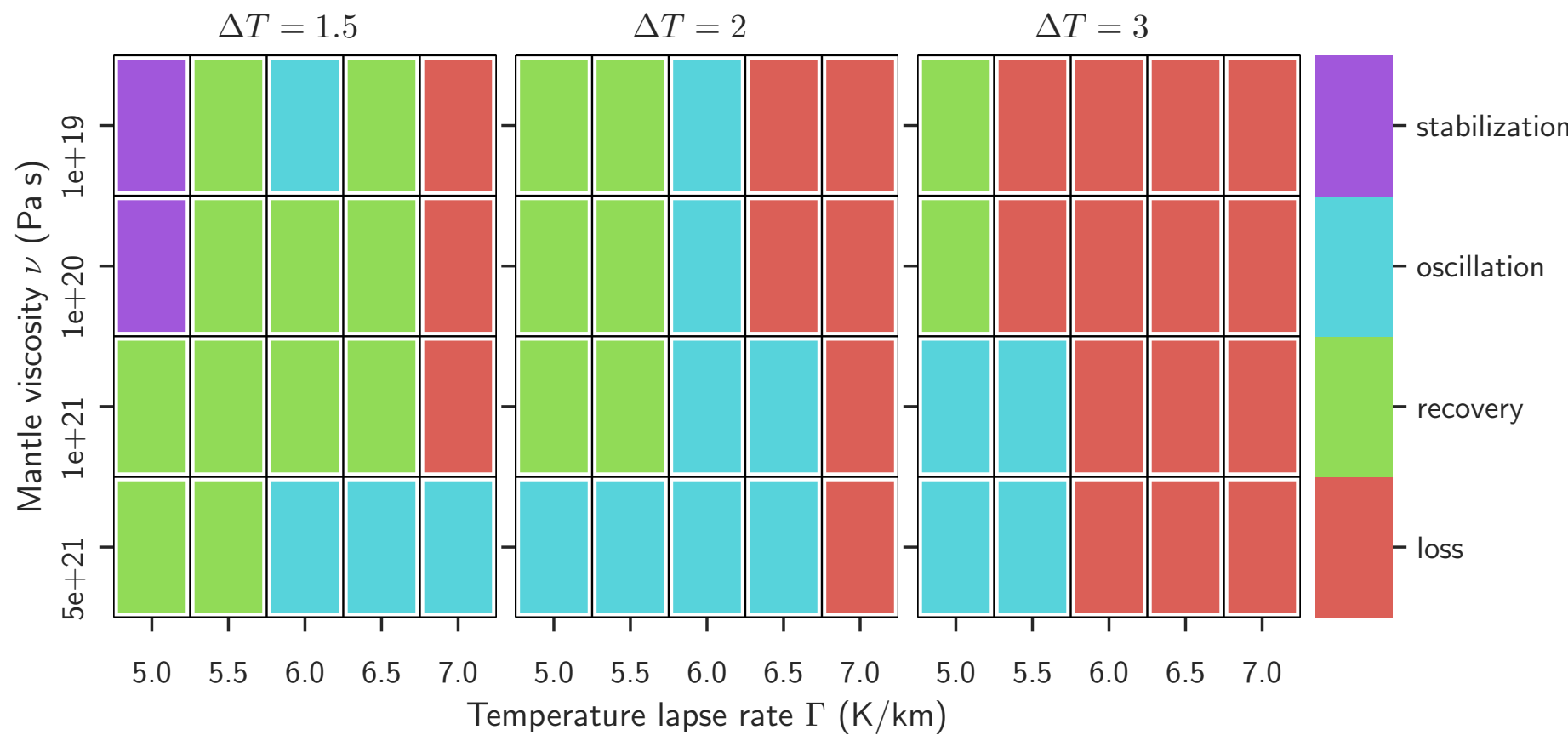

Figure 4. Dynamical regimes of Greenland ice sheet evolution for three different warming temperatures, $\Delta T=1.5 \mathrm{~K}, 2 \mathrm{~K}$, and $3 \mathrm{~K}$. The evolution regime of the Greenland Ice Sheet volume is indicated by the color code. Purple indicates immediate stabilization to a stable state, which preserves more than $90 \%$ of the initial ice sheet volume, without passing a minimum. Green indicates, that the ice sheet volume recovers permanently after passing a minimum first. Blue indicates, that the ice sheet volume does not recover permanently, but shows self-sustained oscillations on a long time scale instead. Red indicates a permanent loss of ice sheet volume.

\subsubsection{Dynamic regimes}

To gain a better understanding of the dynamic regimes of the GrIS we tested the long-term response of the ice-sheet volume to warming in the full-factorial parameter space $\Delta T, \Gamma$ and $\nu$ with values given in Table 1 . As stated above in Section 3.1 four qualitatively different response regimes can be distinguished: (o) Direct stabilization into a new equilibrium state which preserves $90 \%$ or more of the initial ice volume. (i) Recovery to a stable state after an initial ice loss. (ii) Self-sustained oscillations and (iii) Irreversible loss of a large portion of the ice.

With increasing temperature anomalies $\Delta T$ a larger portion of the parameter space experiences irreversible ice loss (iii) (Figure 4). For a warming temperature of $3 \mathrm{~K}$ for example, irreversible ice loss is observed for lapse rates greater or equal than $6 \mathrm{~K} / \mathrm{km}$ for all mantle viscositites and for $5.5 \mathrm{~K} / \mathrm{km}$ for mantle viscosities lower or equal to $1 \mathrm{e}+20 \mathrm{~Pa} \cdot \mathrm{s}$.

Moreover, increasing temperature lapse rate promotes irreversible ice loss, for instance at $\Gamma=7 \mathrm{~K} / \mathrm{km}$, irreversible ice loss occurs for warming temperatures of $2 \mathrm{~K}$ or warmer, regardless of the choice for the mantle viscosity (see Figure 4 ) and also for most simulations with $\Delta T=1.5 \mathrm{~K}$. 


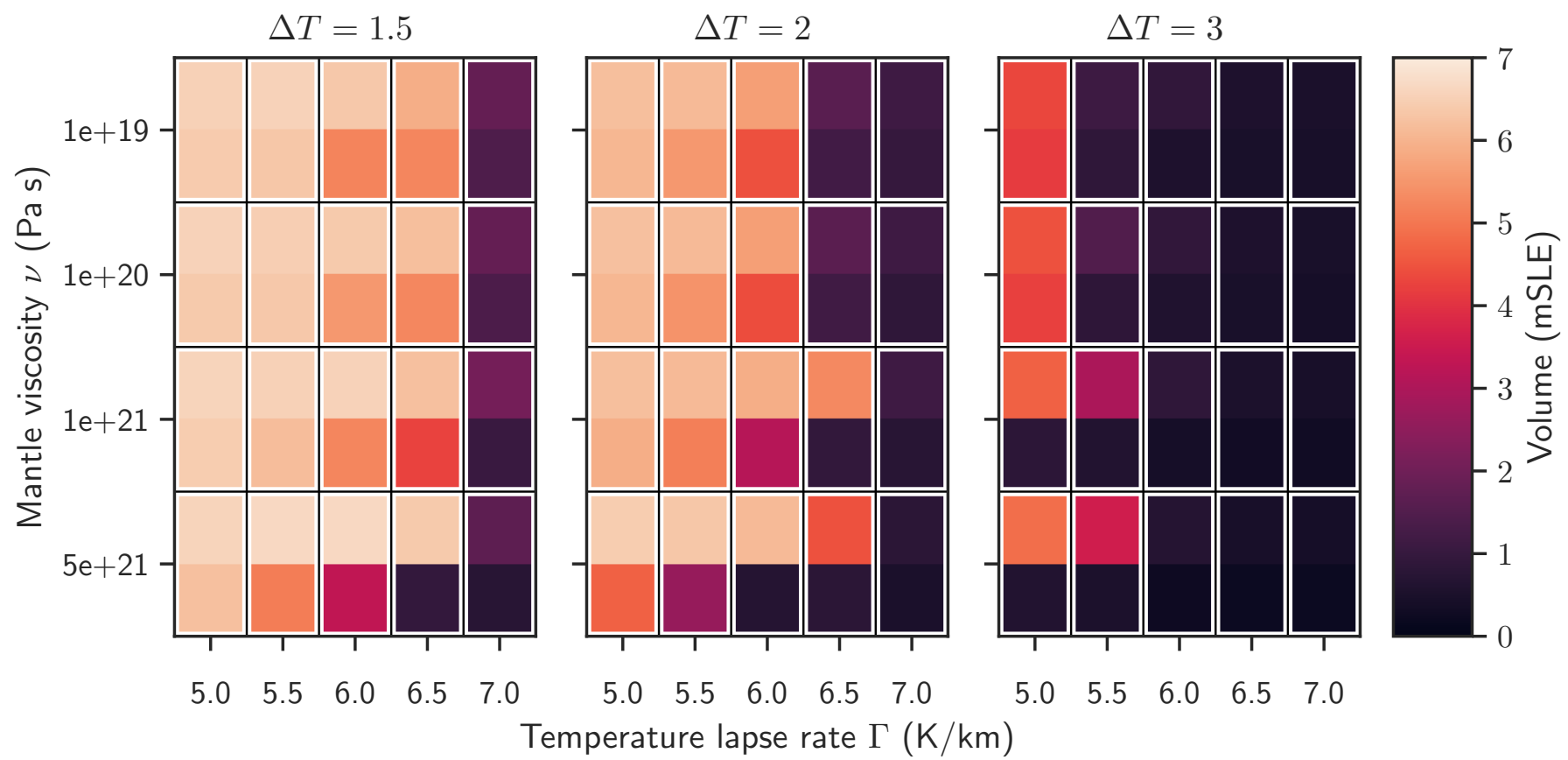

Figure 5. Minimal and maximal volume after initial ice loss for three different warming temperatures, $\Delta T=1.5 \mathrm{~K}, 2 \mathrm{~K}$, and $3 \mathrm{~K}$. Two pixels represent the minimal (lower) and the maximal (upper) long-term volume for each parameter combinations. The minimal and maximal long-term volume is defined by the minimum or the maximum of the volume after passing the initial minimum. A significant difference between the minimal and the maximal volume indicates oscillation.

Direct stabilization without going though a minimum (o) is only realized for the lowest temperature anomaly $\Delta T=1.5 \mathrm{~K}$ and at the lowest lapse rate $\Gamma=5 \mathrm{~K}$. While recovery or stabilization are the most prevalent regimes for low warming temperatures $(1.5 \mathrm{~K})$ in the tested parameters space, the oscillatory regime is realized most often at temperature anomalies of $2 \mathrm{~K}$. High mantle viscosities promote oscillations of the ice sheet volume as they lead to a slower response of the bedrock to changes in ice loss and thereby allow for a stronger retreat phase and thereby a faster initial ice loss with warming, as seen in Fig. 2. On the other hand, the more pronounced retreat initiates a strong bedrock response which supports the recovery. However, the recovered state is not in equilibrium with the bedrock, and thereby a self-sustained oscillation can be triggered.

\subsubsection{Minimum and maximum ice volume for recovery or oscillation regimes}

The long-term response of the Greenland Ice Sheet volume to temperature anomalies can be characterized by the minimal and maximal long-term volume, defined as the minimal and maximal volume attained after passing an initial minimum. In the dynamic regimes of stabilization, recovery, and permanent ice loss the minimal and maximal long-term volumes are therefore almost identical. The absolute values of the minimal and maximal long-term volume determine how much ice is lost and the difference between them shows how large the amplitude of the oscillation is. The minimal and maximal long-term volumes are 


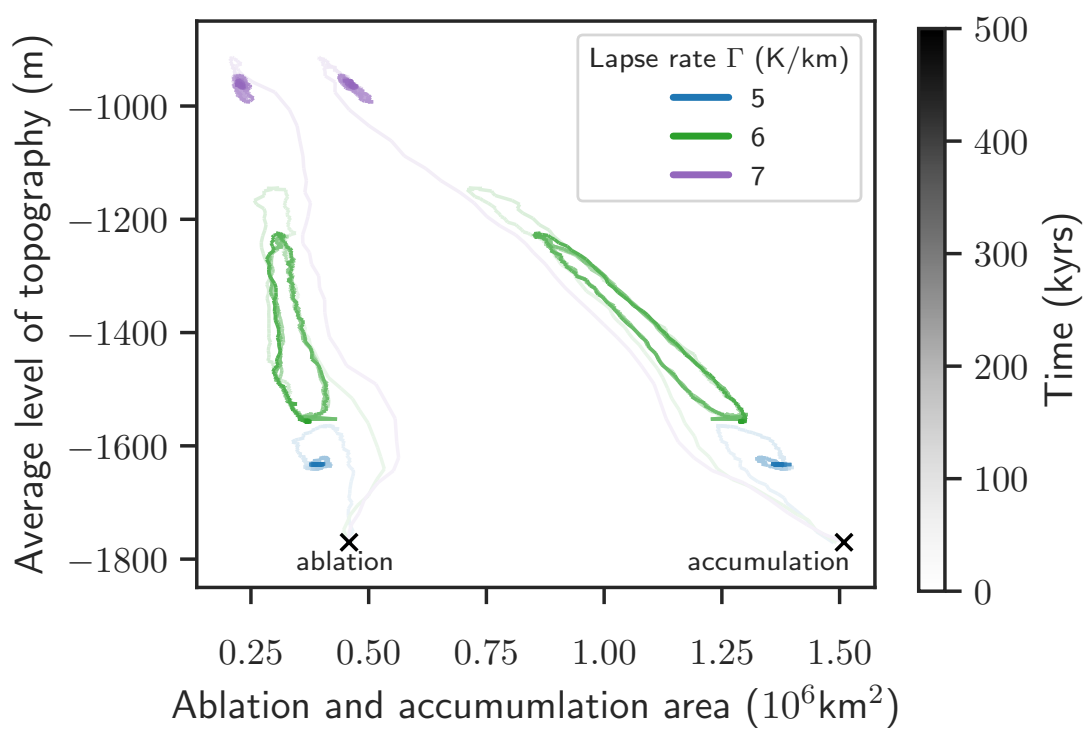

Figure 6. State space trajectories for different regimes for the three different lapse rates $\Gamma=[5,6,7] \mathrm{K} / \mathrm{km}$. The curves represent the average height of the bedrock topography vs. the ablation and the accumulation area. Blue: Lapse rate $\Gamma=5 \mathrm{~K} / \mathrm{km}$, recovery of the ice volume. Green: Lapse rate $\Gamma=6 \mathrm{~K} / \mathrm{km}$, oscillation of the ice volume. Purple: Lapse rate $\Gamma=7 \mathrm{~K} / \mathrm{km}$, irreversible loss of the ice volume.

visualized in Figure 5. Here, two values are shown for each parameter combination. The upper pixels represent the maximum long-term volume, while the lower pixel represents the minimum long-term volume. A comparison to the regime shown in Figure 4 reveals that both volumes are high if the ice volume is stabilized directly or recovers, and both volumes are low if the ice is permanently lost. Oscillations are characterized by a significant difference between the minimal and maximal longterm volume. Generally, the absolute values for either stabilized, oscillating or lost volume decrease with increasing warming. The amplitude of oscillations is highest for high mantle viscosities, since the slow response time associated with high mantle viscosities allows for more ice loss but also for a stronger recovery.

\subsection{State space trajectories}

Here we analyze the different dynamic regimes of the Greenland Ice Sheet via their trajectories through state space. The full state space of an ice sheet has a very high dimensionality and even with the simplifications made by numerical modelling, the full state space remains inaccessible. Here we choose the projection of the state to three state variables: The temporal evolution of the topography altitude of the glaciated areas on the one hand and the ablation or accumulation area of the ice sheet on the other hand. In both cases the variables are averaged over glaciated areas rather than over a fixed area (e.g. the initial ice sheet area), because this is where they affect the ice sheet. For instance the bedrock uplift in a region which has (permanently) lost its ice does not take part in the feedback as described in Fig. 1. The average topography altitude can change either via glacial isostatic adjustment while the ice sheet area is constant or by changing the ice sheet area at constant topography or 
a combination of those two processes. The ablation or accumulation area can either change though changes in the ice-sheet area at constant climatic mass balance or via changing the climatic mass balance but keeping the ice-sheet area constant (or a combination of those two processes).

We interpret the topography altitude as a measure of the GIA feedback and the accumulation and ablation area as a measure 5 for the climatic processes.

We can distinguish three different "phase space trajectories" for the different regimes: recovery after an initial ice loss (i), oscillation (ii) and ice-sheet collapse (iii). All of the simulations shown here are at $\Delta T=2 \mathrm{~K}$ and with the mantle viscosity of $\nu=1 \times 10^{21} \mathrm{~Pa} \cdot \mathrm{s}$.

For $\Gamma=5 \mathrm{~K} / \mathrm{km}$ (blue curves in Figure 2 (A) and Figure 6), the ice sheet is in the recovery regime. Both, the accumulation / ablation areas and the average topography diverge the least from the starting point compared to the other simulations. The trajectories for both accumulation and ablation area spiral quickly into a fixed point. The trajectory for the ablation area follows a counterclockwise spiral while the trajectory for the accumulation area follows a clockwise spiral. The trajectory for the ablation area starts out almost vertically upwards, only little change in the ablation area is observed. The accumulation however shrinks while the bedrock elevation rises. The turning point is characterized by a shrinking ablation area, a rising accumulation area and a depression in bedrock elevation. Here, changes in accumulation area seem to be more important than the changes in the ablation area and to drive the dynamics. Moreover, the ablation and the accumulation area do not seem to be independent, they show, as expected, an anticorrelation.

For $\Gamma=6 \mathrm{~K} / \mathrm{km}$ (green curves in Figure 2 (A) and Figure 6) the ice sheet is in the oscillation regime. The trajectories spiral into a closed loop rather than a fixed point. Again, the trajectory with the ablation area goes counter-clockwise while the trajectory for the accumulation area goes clockwise. In absolute terms the accumulation area changes more drastically than the ablation area, an indication that the change in accumulation area drives the ice loss. The total change in ice-sheet area is reflected through the sum of ablation and accumulation area. Even though the trajectories form a closed loop in this simulation, there is no perfect periodicity. In particular the first loop in the trajectory is larger than the subsequent quasi-periodic behavior.

The atmospheric lapse rate of $\Gamma=7 \mathrm{~K} / \mathrm{km}$ (purple curves in Figure 2 (A) and Figure 6) leads to irreversible ice-sheet collapse under these parameters. The trajectories approach again a fixed point. Both the accumulation and the ablation area are smallest, compared to the other two lapse rate simulations, indicating that the total area of the ice sheet is also small. Again, the absolute change in accumulation area is more drastic than the change in ablation area. In addition, the change in average level of bedrock topography is highest. As indicated beforehand, this is both related to the bedrock uplift (most ice loss allows for the strongest uplift) as well as to the fact that the remaining ice retreats to high altitude mountainous areas with a lot of precipitation and comparatively low temperatures.

The trajectories of the different regimes do not intersect, suggesting that the phase space is well represented. 


\section{Discussion}

In this manuscript, we show how the negative glacial isostatic adjustment feedback (connecting ice sheet and solid Earth) can counteract the positive melt-elevation feedback (connecting atmosphere and ice sheet) and thus the long-term ice loss of the Greenland Ice Sheet under warming temperatures. The interaction of both feedbacks determines the dynamic regime and the

stability of the Greenland Ice Sheet. Depending on the individual feedback strengths, expressed through mantle viscosity and atmospheric temperature lapse rate respectively, we find distinct regimes for the evolution of the ice volume: the transition to a new steady state, recovery after an initial ice loss, self-sustained quasi-periodic oscillations or irreversible ice-sheet collapse. Although it is not explicitly studied here, drastic changes in the ice volume of the Greenland Ice Sheet would have implications for the global earth system via global sea level rise, changes in the planetary albedo, and changes in the atmospheric and oceanic circulation patterns as the Jetstream or the Atlantic Meridional Overturning Circulation (AMOC).

The strength of the melt-elevation feedback impacts the vulnerability of the Greenland Ice Sheet to temperature increases: Varying the feedback strength through the atmospheric lapse rate from $5 \mathrm{~K} / \mathrm{km}$ to $7 \mathrm{~K} / \mathrm{km}$ increases the probability of permanent ice loss for global mean temperature anomalies $\Delta T \geq 1.5 \mathrm{~K}$, assuming $150 \%$ of arctic amplification. Increasing the mantle viscosity from $1 \times 10^{19} \mathrm{~Pa} \cdot \mathrm{s}$ to $5 \times 10^{21} \mathrm{~Pa} \cdot \mathrm{s}$ increases the likelihood for self-sustained oscillations and their corresponding amplitude. The characteristic period of oscillation is in the order of $100 \mathrm{kyrs}$, which is rather independent of both, mantle viscosity or temperature lapse rate. However, in case of recovery the associated characteristic response time seems to increase with increasing lapse rates or mantle viscosities.

\subsection{GIA feedback in different contexts}

The impact of the GIA feedback on ice-sheet dynamics has been studied in different contexts. Marine terminating glaciers and ice shelves are particularly sensitive to glacial isostatic rebound, as it can influence the position of the grounding line and how exposed the ice shelf or the glacier front is to warm ocean water (Larour et al., 2019; Whitehouse et al., 2019). Observational evidence pointing to an overshoot and readvance of the grounding line in the Ross Sea, Antarctica, can be explained by the viscous response of the solid Earth to changes in ice load within a confined range of mantle viscosities (Kingslake et al., 2018). Feldmann and Levermann (2017) showed, that the complex interplay of time scales associated with the surge, buildup and stabilization feedbacks could explain Heinrich-like events.

\subsection{GrIS ice volume oscillations in the context of the Earth System}

While oscillations of ice volume have already been discussed in the context of marine ice sheets (Antarctic Ice Sheet, Laurentide Ice Sheet) (Bassis et al., 2017), we here find that the interaction of the melt-elevation feedback and the GIA feedback alone can promote an oscillatory dynamic response.

Hoever, small oscillations in the GrIS ice volume seem to appear in simulations with a coupled ice-sheet and regional climate model (Petrini et al., 2021). Although the oscillatory regime is not studied explicitly by Petrini et al., its appearance indicates that this dynamic regime is unlikely to be an artifact of our particular experimental design. 
The oscillation time are of the same order of magnitude as the time scale of Earth's glaciation cycle, with a dominant period of $41 \mathrm{kyrs}$ before and a period of $100 \mathrm{kys}$ after the Mid-Pleistocene Transition 1.25-0.7 million years ago (Abe-Ouchi et al., 2013; Willeit et al., 2019). While the onset and the termination of glaciation are driven by changes in insolation, climate and earth surface albedo (Ganopolski and Calov, 2011) our results offer a new perspective. The identified oscillatory regime reveals

5 a possible mode of internal climatic variability in the Earth system on time scales on the order of 100 kyrs that may be excited by or interact with orbital forcing, glacial cycles and other slow modes of variability (Ghil and Lucarini, 2020). As such, this oscillatory mode could be relevant in the long-term Earth system response (on the order of $100 \mathrm{kyrs}$ ) to anthropogenic carbon emissions (Talento and Ganopolski, 2021).

Our findings suggest a sequence of dynamic regimes of the Greenland Ice Sheets on the route to destabilization under global warming, within a certain range of lapse rate coefficients: from recovery, via quasi-periodic variations in ice volume to irreversible ice-sheet collapse. This transition might be similar to destabilization scenarios via oscillatory instabilities which have been revealed for other tipping elements in the climate system, such as the Atlantic Meridional Overturning Circulation (AMOC) (Alkhayuon et al., 2019). A relevant area of future research will be to develop a deeper understanding of such ice sheet destabilization routes via the concept of bifurcations (e.g., Hopf and fold bifurcations) in the context of dynamical systems.

The interplay between an amplifying and a mitigating feedback contributes to our understanding of the long-term stability and the resilience of the Greenland Ice Sheet. Therefore we need to identify the most important underlying physical processes and the interactions of the feedbacks at play.

\subsection{Limitations}

This study is based on the results of the ice sheet model PISM coupled to simple models which capture the melt-elevation feedback, namely the positive degree day approach together with an atmospheric temperature lapse rate, and the GIA feedback, namely the Lingle-Clark model. The relative computational efficiency of those models allows us to conduct an ensemble of long-term simulations over 500,000 years exploring different parameter values characterizing the individual feedbacks and warming. This approach fits the conceptual research question of this study.

The Lingle-Clark approach assumes a flat earth with two layers, one elastic and one viscous layer, in contrast to more sophisticated solid Earth models. It also does assume horizontally constant Earth structure and does not solve the self-consistent sea-level equation. However, the relative importance of discharge and melt at the ice-ocean interface decreases with ongoing warming, as the tidewater glaciers retreat and the ice-ocean interface shrinks (Aschwanden et al., 2019). With ongoing coupling efforts between ice-dynamics models and process based solid Earth models, this study is a first step to assessing the importance of the GIA feedback for the stability of the Greenland Ice Sheet.

While the design of the study was chosen in order to allow for long experiments and to cover parts of the parameter space $(\Delta T, \Gamma$, and $\nu)$, it is also one of the main limitations of the study. The coarse resolution of the ice sheet model does not adequately resolve the flow patterns in outlet glaciers, therefore underestimating dynamical ice losses. Moreover, the parameters which govern the ice dynamics, although uncertain, were not varied (Zeitz et al., 2020). 
The choice of the positive degree day (PDD) method in order to compute the climatic mass balance introduces a tends to underestimate the melt area for present climate, while at high temperatures PDD tends to overestimate melt. Moreover, the temperature anomaly is applied in a spatially and temporally constant way and the precipitation pattern remains fixed. So far, scenario-based projections of future global warming are limited until the year 2300, with projections of the temperature evolution and changes in climatic mass balance over the Greenland Ice Sheet as results from regional climate models only available until the end of this century. The aim here, however, is not to present scenario-based projections of future ice losses but rather to study the distinct dynamical states in the "deep future" of the Greenland Ice Sheet in a fundamental way.

\section{Conclusions}

Here we present an analysis of the dynamic regimes in the deep future of the Greenland Ice Sheet. Depending on the amount of warming and the values of the parameters describing the strength of the melt-elevation feedback and the GIA feedback we find that four different dynamic regimes can be realized: 1) Direct stabilization into a new equilibrium state which preserves $90 \%$ or more of the initial ice volume, 2) Recovery to a stable state after an initial ice loss, 3) Self-sustained oscillations, and 4) Irreversible loss of a large portion of the ice. Our model configuration with parameterized melt-elevation feedback and a fast computation of the leading-order GIA effects allows for studying an ensemble of glacial time-scale simulations and provides insight into how the interaction of feedbacks impacts the dynamics of the complex Earth system with implications for Earth system stability and resilience.

Code availability. The PISM source code is freely available.

Author contributions. RW conceived this study. JH prepared and analysed the initial experiments during his Master project, advised by RW and MZ. MZ expanded the experiments, visualized the results and wrote the manuscript, with support from RW and JFD and TA. All authors interpreted and discussed the results. All the authors give their final approval of the article version to be published.

Competing interests. The authors declare no competing interests.

Acknowledgements. We would like to thank Anders Levermann and Fuyuki Saito for fruitful discussion. We are grateful for financial support by the European Research Council Advanced Grant project ERA (Earth Resilience in the Anthropocene, grant ERC-2016-ADG-743080) and the Leibniz Association (project DominoES). MZ is partially supported by the Deutsche Forschungsgemeinschaft (DFG) by grant WI4556/3-1. MZ acknowledges the German Fulbright commission for a PhD program. RW and TA acknowledge support by TiPACCs, PROTECT, PalMod. We further acknowledge the European Regional Development Fund (ERDF), the German Federal Ministry of Education 
https://doi.org/10.5194/esd-2021-100

Preprint. Discussion started: 17 December 2021

(C) Author(s) 2021. CC BY 4.0 License.

(c) (i)

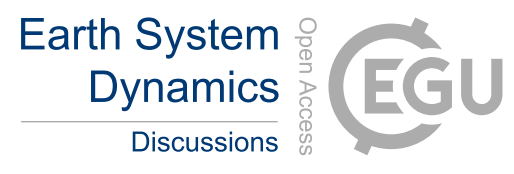

and Research (BMBF) and the Land Brandenburg for supporting this project by providing resources on the high-performance computer system at the Potsdam Institute for Climate Impact Research. Development of PISM is supported by NASA grant NNX17AG65G and NSF grants PLR-1603799 and PLR-1644277. 


\section{References}

Abe-Ouchi, A., Saito, F., Kawamura, K., Raymo, M. E., Okuno, J., Takahashi, K., and Blatter, H.: Insolation-driven 100,000-year glacial cycles and hysteresis of ice-sheet volume, Nature, 500, 190-193, https://doi.org/10.1038/nature12374, 2013.

Adhikari, S., Ivins, E. R., and Larour, E. Y.: Mass transport waves amplified by intense Greenland melt and detected in solid Earth deformation, Geophysical Research Letters, 44, 4965-4975, https://doi.org/10.1002/2017GL073478, 2017.

Adhikari, S., Milne, G. A., Caron, L., Khan, S. A., Kjeldsen, K. K., Nilsson, J., Larour, E. Y., and Ivins, E. R.: Decadal to Centennial Timescale Mantle Viscosity Inferred From Modern Crustal Uplift Rates in Greenland, Geophysical Research Letters, 48, 1-11, https://doi.org/10.1029/2021g1094040, 2021.

Albrecht, T., Winkelmann, R., and Levermann, A.: Glacial-cycle simulations of the Antarctic Ice Sheet with the Parallel Ice Sheet Model (PISM) - Part 1: Boundary conditions and climatic forcing, The Cryosphere, 14, 599-632, https://doi.org/10.5194/tc-14-599-2020, https: //tc.copernicus.org/articles/14/599/2020/, 2020.

Alkhayuon, H., Ashwin, P., Jackson, L. C., Quinn, C., and Wood, R. A.: Basin bifurcations, oscillatory instability and rate-induced thresholds for Atlantic meridional overturning circulation in a global oceanic box model, Proceedings of the Royal Society A: Mathematical, Physical and Engineering Sciences, 475, https://doi.org/10.1098/rspa.2019.0051, 2019.

Aschwanden, A., Fahnestock, M. A., Truffer, M., Brinkerhoff, D. J., Hock, R., Khroulev, C., Mottram, R. H., and Khan, S. A.: Contribution of the Greenland Ice Sheet to sea level over the next millennium, Science Advances, 5, eaav9396, https://doi.org/10.1126/sciadv.aav9396, http://advances.sciencemag.org/lookup/doi/10.1126/sciadv.aav9396, 2019.

Barletta, V. R., Bevis, M., Smith, B. E., Wilson, T., Brown, A., Bordoni, A., Willis, M. J., Khan, S. A., Rovira-Navarro, M., Dalziel, I., Smalley, R., Kendrick, E., Konfal, S., Caccamise, D. J., Aster, R. C., Nyblade, A., and Wiens, D. A.: Observed rapid bedrock uplift in amundsen sea embayment promotes ice-sheet stability, Science, 360, 1335-1339, https://doi.org/10.1126/science.aao1447, 2018.

Bassis, J. N., Petersen, S. V., and Mac Cathles, L.: Heinrich events triggered by ocean forcing and modulated by isostatic adjustment, Nature, 542, 332-334, https://doi.org/10.1038/nature21069, 2017.

Boers, N. and Rypdal, M.: Critical slowing down suggests that the western Greenland Ice Sheet is close to a tipping point, Proceedings of the National Academy of Sciences of the United States of America, 118, 1-7, https://doi.org/10.1073/pnas.2024192118, 2021.

Braithwaite, R. J.: Positive degree-day factors for ablation on the Greenland ice sheet studied by energy-balance modelling, Journal of Glaciology, 41, 153-160, https://doi.org/10.1017/S0022143000017846, 1995.

Bueler, E. and Brown, J.: Shallow shelf approximation as a "sliding law" in a thermomechanically coupled ice sheet model, Journal of Geophysical Research: Solid Earth, 114, 1-21, https://doi.org/10.1029/2008JF001179, 2009.

Bueler, E. and van Pelt, W.: Mass-conserving subglacial hydrology in the Parallel Ice Sheet Model version 0.6, Geoscientific Model Development, 8, 1613-1635, https://doi.org/10.5194/gmd-8-1613-2015, https://gmd.copernicus.org/articles/8/1613/2015/, 2015.

Bueler, E., Lingle, C. S., and Brown, J.: Fast computation of a viscoelastic deformable Earth model for ice-sheet simulations, Annals of Glaciology, 46, 97-105, https://doi.org/10.3189/172756407782871567, 2007.

Crucifix, M.: Oscillators and relaxation phenomena in Pleistocene climate theory, Philosophical Transactions of the Royal Society A: Mathematical, Physical and Engineering Sciences, 370, 1140-1165, https://doi.org/10.1098/rsta.2011.0315, 2012.

35 De Boer, B., Stocchi, P., and Van De Wal, R. S.: A fully coupled 3-D ice-sheet-sea-level model: Algorithm and applications, Geoscientific Model Development, 7, 2141-2156, https://doi.org/10.5194/gmd-7-2141-2014, 2014. 
Denton, G. H., Anderson, R. F., Toggweiler, J. R., Edwards, R. L., Schaefer, J. M., and Putnam, A. E.: The Last Glacial Termination, Science, 328, 1652-1656, https://doi.org/10.1126/science.1184119, 2010.

Dietrich, R., Rülke, A., and Scheinert, M.: Present-day vertical crustal deformations in West Greenland from repeated GPS observations, Geophysical Journal International, 163, 865-874, https://doi.org/10.1111/j.1365-246X.2005.02766.x, 2005.

5 Farrell, W. E. and Clark, J. A.: On Postglacial Sea Level, Geophysical Journal of the Royal Astronomical Society, 46, 647-667, https://doi.org/10.1111/j.1365-246X.1976.tb01252.x, 1976.

Fausto, R. S., Ahlstrøm, A. P., Van As, D., Bøggild, C. E., and Johnsen, S. J.: A new present-day temperature parameterization for Greenland, Journal of Glaciology, 55, 95-105, https://doi.org/10.3189/002214309788608985, 2009.

Feldmann, J. and Levermann, A.: From cyclic ice streaming to Heinrich-like events: the grow-and-surge instability in the Parallel Ice Sheet

Model, The Cryosphere, 11, 1913-1932, https://doi.org/10.5194/tc-11-1913-2017, https://tc.copernicus.org/articles/11/1913/2017/, 2017.

Fettweis, X., Hofer, S., Krebs-Kanzow, U., Amory, C., Aoki, T., Berends, C. J., Born, A., Box, J. E., Delhasse, A., Fujita, K., Gierz, P., Goelzer, H., Hanna, E., Hashimoto, A., Huybrechts, P., Kapsch, M.-1., King, M. D., Kittel, C., Lang, C., Langen, P. L., Lenaerts, J. T., Liston, G. E., Lohmann, G., Mernild, S. H., Mikolajewicz, U., Modali, K., Mottram, R. H., Niwano, M., Noël, B. P. Y., Ryan, J. C., Smith, A., Streffing, J., Tedesco, M., van de Berg, W. J., Van Den Broeke, M. R., van de Wal, R. S. W., van Kampenhout, L., Wilton, D. J., Wouters, B., Ziemen, F. A., and Zolles, T.: GrSMBMIP: intercomparison of the modelled 1980-2012 surface mass balance over the Greenland Ice Sheet, The Cryosphere, 14, 3935-3958, https://doi.org/10.5194/tc-14-3935-2020, https://tc.copernicus.org/articles/14/3935/2020/, 2020.

Fleming, K. and Lambeck, K.: Constraints on the Greenland Ice Sheet since the Last Glacial Maximum from sea-level observations and glacial-rebound models, Quaternary Science Reviews, 23, 1053-1077, https://doi.org/10.1016/j.quascirev.2003.11.001, 2004.

Frederikse, T., Landerer, F. W., Caron, L., Adhikari, S., Parkes, D., Humphrey, V. W., Dangendorf, S., Hogarth, P., Zanna, L., Cheng, L., and

Wu, Y. H.: The causes of sea-level rise since 1900, Nature, 584, 393-397, https://doi.org/10.1038/s41586-020-2591-3, http://dx.doi.org/ 10.1038/s41586-020-2591-3, 2020.

Ganopolski, A. and Calov, R.: The role of orbital forcing, carbon dioxide and regolith in 100 kyr glacial cycles, Climate of the Past, 7 , 1415-1425, https://doi.org/10.5194/cp-7-1415-2011, 2011.

Gardner, A. S., Sharp, M. J., Koerner, R. M., Labine, C., Boon, S., Marshall, S. J., Burgess, D. O., and Lewis, D.: Near-surface temperature lapse rates over arctic glaciers and their implications for temperature downscaling, Journal of Climate, 22, 4281-4298, https://doi.org/10.1175/2009JCLI2845.1, 2009.

Ghil, M. and Lucarini, V.: The physics of climate variability and climate change, Reviews of Modern Physics, 92, 35002, https://doi.org/10.1103/RevModPhys.92.035002, https://doi.org/10.1103/RevModPhys.92.035002, 2020.

Gomez, N., Pollard, D., and Mitrovica, J. X.: A 3-D coupled ice sheet - sea level model applied to Antarctica through the last 40 ky, Earth and Planetary Science Letters, 384, 88-99, https://doi.org/10.1016/j.eps1.2013.09.042, http://dx.doi.org/10.1016/j.eps1.2013.09.042, 2013.

Gomez, N., Latychev, K., and Pollard, D.: A coupled ice sheet-sea level model incorporating 3D earth structure: Variations in Antarctica during the Last Deglacial Retreat, Journal of Climate, 31, 4041-4054, https://doi.org/10.1175/JCLI-D-17-0352.1, 2018.

Gomez, N., Weber, M. E., Clark, P. U., Mitrovica, J. X., and Han, H. K.: Antarctic ice dynamics amplified by Northern Hemisphere sea-level forcing, Nature, 587, 600-604, https://doi.org/10.1038/s41586-020-2916-2, http://dx.doi.org/10.1038/s41586-020-2916-2, 2020.

35 Haeger, C., Kaban, M. K., Tesauro, M., Petrunin, A. G., and Mooney, W. D.: 3-D Density, Thermal, and Compositional Model of the Antarctic Lithosphere and Implications for Its Evolution, Geochemistry, Geophysics, Geosystems, 20, 688-707, https://doi.org/10.1029/2018GC008033, 2019. 
Hagedoorn, J. M., Wolf, D., and Martinec, Z.: An estimate of global mean sea-level rise inferred from tide-gauge measurements using glacialisostatic models consistent with the relative sea-level record, Pure and Applied Geophysics, 164, 791-818, https://doi.org/10.1007/s00024007-0186-7, 2007.

Hanna, E., Huybrechts, P., Janssens, I., Cappelen, J., Steffen, K., and Stenhens, A.: Runoff and mass balance of the Greenland ice sheet: 1958-2003, Journal of Geophysical Research Atmospheres, 110, 1-16, https://doi.org/10.1029/2004JD005641, 2005.

Joughin, I., Smith, B. E., and Howat, I.: Greenland Ice Mapping Project: Ice Flow Velocity Variation at sub-monthly to decadal time scales, The Cryosphere Discussions, pp. 1-30, https://doi.org/10.5194/tc-12-2211-2018, 2018.

Khan, S. A., Wahr, J., Leuliette, E., van Dam, T., Larson, K. M., and Francis, O.: Geodetic measurements of postglacial adjustments in Greenland, Journal of Geophysical Research: Solid Earth, 113, 1-16, https://doi.org/10.1029/2007JB004956, 2008.

Khan, S. A., Sasgen, I., Bevis, M., van Dam, T., Bamber, J. L., Wahr, J., Willis, M., Kjær, K. H., Wouters, B., Helm, V., Csatho, B., Fleming, K., Bjørk, A. A., Aschwanden, A., Knudsen, P., and Munneke, P. K.: Geodetic measurements reveal similarities between post-Last Glacial Maximum and present-day mass loss from the Greenland ice sheet, Science Advances, 2, e1600931, https://doi.org/10.1126/sciadv.1600931, http://advances.sciencemag.org.biblioplanets.gate.inist.fr/content/2/9/e1600931, 2016.

Kingslake, J., Scherer, R. P., Albrecht, T., Coenen, J., Powell, R. D., Reese, R., Stansell, N. D., Tulaczyk, S., Wearing, M. G., and Whitehouse, P. L.: Extensive retreat and re-advance of the West Antarctic Ice Sheet during the Holocene, Nature, 558, 430-434, https://doi.org/10.1038/s41586-018-0208-x, http://dx.doi.org/10.1038/s41586-018-0208-xhttp://www.nature.com/articles/ s41586-018-0208-x, 2018.

Konrad, H., Sasgen, I., Pollard, D., and Klemann, V.: Potential of the solid-Earth response for limiting long-term West Antarctic Ice Sheet retreat in a warming climate, Earth and Planetary Science Letters, 432, 254-264, https://doi.org/10.1016/j.epsl.2015.10.008, http://dx.doi. org/10.1016/j.epsl.2015.10.008, 2015.

Lambeck, K., Rouby, H., Purcell, A., Sun, Y., and Sambridge, M.: Sea level and global ice volumes from the Last Glacial Maximum to the Holocene, Proceedings of the National Academy of Sciences of the United States of America, 111, 15296-15303, https://doi.org/10.1073/pnas.1411762111, 2014.

Larour, E. Y., Seroussi, H., Adhikari, S., Ivins, E. R., Caron, L., Morlighem, M., and Schlegel, N.: Slowdown in Antarctic mass loss from solid Earth and sea-level feedbacks, Science, 364, eaav7908, https://doi.org/10.1126/science.aav7908, https://www.sciencemag.org/lookup/doi/ 10.1126/science.aav7908, 2019.

Lau, H. C., Mitrovica, J. X., Austermann, J., Crawford, O., Al-Attar, D., and Latychev, K.: Inferences of mantle viscosity based on ice age data sets: Radial structure, Journal of Geophysical Research: Solid Earth, 121, 6991-7012, https://doi.org/10.1002/2016JB013043, 2016.

Le Meur, E. and Huybrechts, P.: A comparison of different ways of dealing with isostasy: examples from modelling the Antarctic ice sheet during the last glacial cycle, Annals of Glaciology, 23, 309-317, https://doi.org/10.1017/S0260305500013586, https://www.cambridge. org/core/product/identifier/S0260305500013586/type/journal\{_\}article, 1996.

Le Meur, E. and Huybrechts, P.: Present-day uplift patterns over Greenland from a coupled ice-sheet/visco-elastic bedrock model, Geophysical Research Letters, 25, 3951-3954, https://doi.org/10.1029/1998GL900052, 1998.

Lecavalier, B. S., Milne, G. A., Simpson, M. J., Wake, L. M., Huybrechts, P., Tarasov, L., Kjeldsen, K. K., Funder, S., Long, A. J., Woodroffe, S., Dyke, A. S., and Larsen, N. K.: A model of Greenland ice sheet deglaciation constrained by observations of relative sea level and ice extent, Quaternary Science Reviews, 102, 54-84, https://doi.org/10.1016/j.quascirev.2014.07.018, http://dx.doi.org/10.1016/j.quascirev. 2014.07.018, 2014. 
Lenton, T. M., Rockström, J., Gaffney, O., Rahmstorf, S., Richardson, K., Steffen, W., and Shellnhuber, H. J.: Climate tipping points - too risky to bet against, Nature, 575, 592-595, 2019.

Levermann, A. and Winkelmann, R.: A simple equation for the melt elevation feedback of ice sheets, The Cryosphere, 10, 1799-1807, https://doi.org/10.5194/tc-10-1799-2016, https://tc.copernicus.org/articles/10/1799/2016/, 2016.

5 Levermann, A., Albrecht, T., Winkelmann, R., Martin, M. A., Haseloff, M., and Joughin, I.: Kinematic first-order calving law implies potential for abrupt ice-shelf retreat, The Cryosphere, 6, 273-286, https://doi.org/10.5194/tc-6-273-2012, https://tc.copernicus.org/articles/ 6/273/2012/, 2012.

Levermann, A., Clark, P. U., Marzeion, B., Milne, G. A., Pollard, D., Radic, V., and Robinson, A.: The multimillennial sea-level commitment of global warming., Proceedings of the National Academy of Sciences, 110, 13 745-13 750, https://doi.org/10.1073/pnas.1219414110, http://www.ncbi.nlm.nih.gov/pubmed/23858443, 2013.

Lingle, C. S. and Clark, J. A.: A numerical model of interactions between a marine ice sheet and the solid Earth: application to a West Antarctic ice stream., Journal of Geophysical Research, 90, 1100-1114, https://doi.org/10.1029/JC090iC01p01100, 1985.

Locarnini, R. A., Mishonov, A., Baranova, O., Boyer, T., Zweng, M., Garcia, H. E., Reagan, J., Seidov, D., Weathers, K., Paver, C., and Smolyar, I. V.: WORLD OCEAN ATLAS 2018 Volume 1: Temperature, Tech. rep., 2019.

Martinec, Z.: Spectral-finite element approach to three-dimensional viscoelastic relaxation in a spherical earth, Geophysical Journal International, 142, 117-141, https://doi.org/10.1046/j.1365-246X.2000.00138.x, 2000.

Milne, G. A., Latychev, K., Schaeffer, A., Crowley, J. W., Lecavalier, B. S., and Audette, A.: The influence of lateral Earth structure on glacial isostatic adjustment in Greenland, Geophysical Journal International, 214, 1252-1266, https://doi.org/10.1093/GJI/GGY189, 2018.

Mordret, A.: Uncovering the Iceland Hot Spot Track Beneath Greenland, Journal of Geophysical Research: Solid Earth, 123, 4922-4941, https://doi.org/10.1029/2017JB015104, 2018.

Morlighem, M., Bondzio, J., Seroussi, H., Rignot, E., Larour, E. Y., Humbert, A., and Rebuffi, S.: Modeling of Store Gletscher's calving dynamics, West Greenland, in response to ocean thermal forcing, Geophysical Research Letters, 43, 2659-2666, https://doi.org/10.1002/2016GL067695, 2016.

Morlighem, M., Williams, C. N., Rignot, E., An, L., Arndt, J. E., Bamber, J. L., Catania, G., Chauché, N., Dowdeswell, J. A., Dorschel, B., Fenty, I. G., Hogan, K., Howat, I., Hubbard, A., Jakobsson, M., Jordan, T. M., Kjeldsen, K. K., Millan, R., Mayer, L., Mouginot, J., Noël, B. P. Y., O’Cofaigh, C., Palmer, S., Rysgaard, S., Seroussi, H., Siegert, M. J., Slabon, P., Straneo, F., Van Den Broeke, M. R., Weinrebe, W., Wood, M., and Zinglersen, K. B.: BedMachine v3: Complete Bed Topography and Ocean Bathymetry Mapping of Greenland From Multibeam Echo Sounding Combined With Mass Conservation, Geophysical Research Letters, 44, 11,051-11,061, https://doi.org/10.1002/2017GL074954, 2017.

Mouginot, J., Rignot, E., Bjørk, A. A., Van Den Broeke, M. R., Millan, R., Morlighem, M., Noël, B. P. Y., Scheuchl, B., and Wood, M.: Fortysix years of Greenland Ice Sheet mass balance from 1972 to 2018, Proceedings of the National Academy of Sciences, 116, 201904 242, https://doi.org/10.1073/pnas.1904242116, http://www.pnas.org/lookup/doi/10.1073/pnas.1904242116, 2019.

Noël, B. P. Y., van de Berg, W. J., Lhermitte, S., and van den Broeke, M. R.: Rapid ablation zone expansion amplifies north Greenland mass loss, Science Advances, 5, 2-11, https://doi.org/10.1126/sciadv.aaw0123, 2019.

35 Peltier, W. R. and Drummong, R.: Rheological stratification of the lithosphere: A direct inference based upon the geodetically observed pattern of the glacial isostatic adjustment of the North American continent, Geophysical Research Letters, 35, 1-5, https://doi.org/10.1029/2008GL034586, 2008. 
Petrini, M., Vizcaino, M., Sellevold, R., Muntjewerf, L., Georgiou, S., Scherrenberg, M. D. W., Lipscomb, W., and Leguy, G. R.: Multimillennial response of the Greenland Ice Sheet to anthropogenic warming, in: EGU General Assembly 2021, online, 19-30 Apr 2021, EGU21-12958, https://doi.org/doi.org/10.5194/egusphere-egu21-12958, 2021.

Pico, T., Birch, L., Weisenberg, J., and Mitrovica, J. X.: Refining the Laurentide Ice Sheet at Marine Isotope Stage 3: A databased approach combining glacial isostatic simulations with a dynamic ice model, Quaternary Science Reviews, 195, 171-179, https://doi.org/10.1016/j.quascirev.2018.07.023, https://doi.org/10.1016/j.quascirev.2018.07.023, 2018.

Pollard, D., Gomez, N., and Deconto, R. M.: Variations of the Antarctic Ice Sheet in a Coupled Ice Sheet-Earth-Sea Level Model: Sensitivity to Viscoelastic Earth Properties, Journal of Geophysical Research: Earth Surface, 122, 2124-2138, https://doi.org/10.1002/2017JF004371, 2017.

Powell, E. M., Gomez, N., Hay, C., Latychev, K., and Mitrovica, J. X.: Viscous effects in the solid earth response to modern Antarctic ice mass flux: Implications for geodetic studies of WAIS stability in a warming world, Journal of Climate, 33, 443-459, https://doi.org/10.1175/JCLI-D-19-0479.1, 2020.

Powell, E. M., Pan, L., Hoggard, M. J., Latychev, K., Gomez, N., Austermann, J., and Mitrovica, J. X.: The impact of 3-D Earth structure on far-field sea level following interglacial West Antarctic Ice Sheet collapse, Quaternary Science Reviews, 273, 107256, https://doi.org/10.1016/j.quascirev.2021.107256, https://doi.org/10.1016/j.quascirev.2021.107256, 2021.

Rignot, E. and Mouginot, J.: Ice flow in Greenland for the International Polar Year 2008-2009, Geophysical Research Letters, 39, 1-7, https://doi.org/10.1029/2012GL051634, 2012.

Robinson, A., Calov, R., and Ganopolski, A.: Multistability and critical thresholds of the Greenland ice sheet, Nature Climate Change, 2, 429-432, https://doi.org/10.1038/nclimate1449, http://dx.doi.org/10.1038/nclimate1449, 2012.

Schumacher, M., King, M. A., Rougier, J., Sha, Z., Khan, S. A., and Bamber, J. L.: A new global GPS data set for testing and improving modelled GIA uplift rates, Geophysical Journal International, 214, 2164-2176, https://doi.org/10.1093/gji/ggy235, 2018.

Simpson, M. J., Milne, G. A., Huybrechts, P., and Long, A. J.: Calibrating a glaciological model of the Greenland ice sheet from the Last Glacial Maximum to present-day using field observations of relative sea level and ice extent, Quaternary Science Reviews, 28, 1631-1657, https://doi.org/10.1016/j.quascirev.2009.03.004, http://dx.doi.org/10.1016/j.quascirev.2009.03.004, 2009.

Steffen, K. and Box, J.: Surface climatology of the Greenland Ice Sheet: Greenland Climate Network 1995-1999, Journal of Geophysical Research: Atmospheres, 106, 33 951-33 964, https://doi.org/10.1029/2001JD900161, http://doi.wiley.com/10.1029/2001JD900161, 2001.

Talento, S. and Ganopolski, A.: Reduced-complexity model for the impact of anthropogenic CO\&lt;sub\&gt;2\&lt;/sub\&gt; emissions on future glacial cycles, Earth System Dynamics, 12, 1275-1293, https://doi.org/10.5194/esd-12-1275-2021, https://esd.copernicus.org/articles/ 12/1275/2021/, 2021.

30 the PISM authors: PISM, a Parallel Ice Sheet Model, http://www.pism-docs.org, 2018.

Tosi, N., Sabadini, R., Marotta, A. M., and Vermeersen, L. L.: Simultaneous inversion for the Earth's mantle viscosity and ice mass imbalance in Antarctica and Greenland, Journal of Geophysical Research: Solid Earth, 110, 1-14, https://doi.org/10.1029/2004JB003236, 2005.

Vasskog, K., Langebroek, P. M., Andrews, J. T., Nilsen, J. E. Ø., and Nesje, A.: The Greenland Ice Sheet during the last glacial cycle: Current ice loss and contribution to sea-level rise from a palaeoclimatic perspective, Earth-Science Reviews, 150, 45-67, https://doi.org/10.1016/j.earscirev.2015.07.006, http://dx.doi.org/10.1016/j.earscirev.2015.07.006, 2015.

Wahr, J., van Dam, T., Larson, K. M., and Francis, O.: Geodetic measurements in Greenland and their implications, Journal of Geophysical Research: Solid Earth, 106, 16 567-16 581, https://doi.org/10.1029/2001JB000211, http://doi.wiley.com/10.1029/2001JB000211, 2001. 
Weertman, J.: Stability of ice-age ice sheets, Journal of Geophysical Research, 66, 3783-3792, https://doi.org/10.1029/jz066i011p03783, 1961.

Whitehouse, P., Latychev, K., Milne, G. A., Mitrovica, J. X., and Kendall, R.: Impact of 3-D Earth structure on Fennoscandian glacial isostatic adjustment: Implications for space-geodetic estimates of present-day crustal deformations, Geophysical Research Letters, 33, 3-7, https://doi.org/10.1029/2006GL026568, 2006.

Whitehouse, P. L.: Glacial isostatic adjustment modelling: Historical perspectives, recent advances, and future directions, Earth Surface Dynamics, 6, 401-429, https://doi.org/10.5194/esurf-6-401-2018, 2018.

Whitehouse, P. L., Gomez, N., King, M. A., and Wiens, D. A.: Solid Earth change and the evolution of the Antarctic Ice Sheet, Nature Communications, 10, 1-14, https://doi.org/10.1038/s41467-018-08068-y, http://dx.doi.org/10.1038/s41467-018-08068-y, 2019.

Willeit, M. and Ganopolski, A.: The importance of snow albedo for ice sheet evolution over the last glacial cycle, Climate of the Past, 14 , 697-707, https://doi.org/10.5194/cp-14-697-2018, 2018.

Willeit, M., Ganopolski, A., Calov, R., and Brovkin, V.: Mid-Pleistocene transition in glacial cycles explained by declining CO2 and regolith removal, Science Advances, 5, 1-9, https://doi.org/10.1126/sciadv.aav7337, 2019.

Winkelmann, R., Martin, M. A., Haseloff, M., Albrecht, T., Bueler, E., Khroulev, C., and Levermann, A.: The Potsdam Parallel Ice Sheet Model (PISM-PIK) - Part 1: Model description, The Cryosphere, 5, 715-726, https://doi.org/10.5194/tc-5-715-2011, https: //www.the-cryosphere.net/5/715/2011/, 2011.

Zeitz, M., Levermann, A., and Winkelmann, R.: Sensitivity of ice loss to uncertainty in flow law parameters in an idealized one-dimensional geometry, The Cryosphere, 14, 3537-3550, https://doi.org/10.5194/tc-14-3537-2020, https://tc.copernicus.org/articles/14/3537/2020/, 2020.

Zweck, C. and Huybrechts, P.: Modeling of the northern hemisphere ice sheets during the last glacial cycle and glaciological sensitivity, Journal of Geophysical Research Atmospheres, 110, 1-24, https://doi.org/10.1029/2004JD005489, 2005.

Zweng, M. M., Reagan, J. R., Seidov, D., Boyer, T. P., Locarnini, R. A., Garcia, H. E., Mishonov, A. V., Baranova, O. K., Weathers, K. W., Paver, C. R., and Smolyar, I. V.: WORLD OCEAN ATLAS 2018 Volume 2: Salinity, Tech. Rep. September, 2018. 